Research Article

\title{
Contributing to Global Health: Development of a Consensus-Based Whole Systems Research Strategy for Anthroposophic Medicine
}

\author{
G. S. Kienle $\mathbb{D}^{1,2}$ E. Ben-Arye, ${ }^{3}$ B. Berger ${ }^{10},{ }^{4}$ C. Cuadrado Nahum, ${ }^{5}$ T. Falkenberg, \\ G. Kapócs, ${ }^{7}$ H. Kiene, ${ }^{1}$ D. Martin $\mathbb{D}^{8},{ }^{8}$ U. Wolf, ${ }^{9}$ and H. Szöke ${ }^{10}$ \\ ${ }^{1}$ Institute for Applied Epistemology and Medical Methodology, Witten/Herdecke University, Freiburg, Germany \\ ${ }^{2}$ Center for Complementary Medicine, Institute for Infection Prevention and Hospital Epidemiology, Medical Center, \\ Faculty of Medicine, University of Freiburg, Freiburg, Germany \\ ${ }^{3}$ Integrative Oncology Program, Oncology Service, Lin Medical Center, Clalit Health Services, Rappaport Faculty of Medicine, \\ Technion, Haifa, Israel \\ ${ }^{4}$ Institute for Integrative Medicine, Witten/Herdecke University, Freiburg, Germany \\ ${ }^{5}$ Program of Health Policy, Systems and Management, School of Public Health, University of Chile, Santiago, Chile \\ ${ }^{6}$ Department of Neurobiology Care Sciences and Society, Division of Nursing, Research Group Integrative Care, \\ Karolinska Institutet, Stockholm, Sweden \\ ${ }^{7}$ Department of Psychiatry and Psychiatric Rehabilitation, Saint John Hospital, Budapest, Hungary \\ ${ }^{8}$ Integrative and Anthroposophic Medicine, Institute for Integrative Medicine, Witten/Herdecke University, Freiburg, Germany \\ ${ }^{9}$ University of Bern, Institute of Complementary and Integrative Medicine, Bern, Switzerland \\ ${ }^{10}$ Department of CAM, Faculty of Health Sciences, University of Pecs, Pilisszentkereszt, Hungary
}

Correspondence should be addressed to G. S. Kienle; gunver.kienle@ifaemm.de

Received 28 April 2019; Revised 22 August 2019; Accepted 24 September 2019; Published 12 November 2019

Academic Editor: Svein Haavik

Copyright (c) 2019 G. S. Kienle et al. This is an open access article distributed under the Creative Commons Attribution License, which permits unrestricted use, distribution, and reproduction in any medium, provided the original work is properly cited.

Background. Whole medicine and health systems like traditional and complementary medicine systems (T\&CM) are part of healthcare around the world. One key feature of T\&CM is its focus on patient-centered and multimodal care and the integration of intercultural perspectives in a wide range of settings. It may contribute to good health and well being for people as part of the Sustainable Development Goals of the United Nations. The authentic, rigorous, and fair evaluation of such a medical system, with its inherent complexity and individualization, imposes methodological challenges. Hence, we propose a broad research strategy to test and characterize its possible contribution to health. Methods. To develop a research strategy for a specific T\&CM system, Anthroposophic Medicine (AM), applying multimodal integrative healthcare based on a four-level concept of man, we used a three-phase consensus process with experts and key stakeholders, consisting of (1) premeeting methodological literature and AM research review and interviews to supplement or revise items of the research strategy and tailor them to AM research, (2) face-toface consensus meetings further developing and tailoring the strategy, and (3) postmeeting feedback and review, followed by finalization. Results. Currently, AM covers many fields of medical specialties in varied levels of healthcare settings, such as outpatient and inpatient; primary, secondary, and tertiary care; and health education and pedagogy. It is by definition integrated with conventional medicine in the public healthcare system. It applies specific medicines, nursing techniques, arts therapies, eurythmy therapy, rhythmical massage, counseling, and psychotherapy, and it is provided by medical doctors, nurses, therapists, midwives, and nutritionists. A research strategy authentic to this level of complexity should comprise items with a focus on (I) efficacy and effectiveness, divided into (a) evaluation of the multimodal and multidisciplinary medical system as a whole, or of complex multimodal therapy concept, (b) a reasonable amount of methodologically rigorous, confirmatory randomized controlled trials on exemplary pharmacological and nonpharmacological therapies and indications, (c) a wide range of interventions and patient-centered care strategies with less extensive formats like well-conducted small trails, observational studies, and high- 
quality case reports and series, or subgroup analyses from whole-system studies, or health service research; (II) safety; (III) economics; (IV) evidence synthesis; (V) methodologic issues; (VI) biomedical, physiological, pharmacological, pharmaceutical, psychological, anthropological, and nosological issues as well as innovation and development; (VI) patient perspective and involvement, public needs, and ethics; (VII) educational matters and professionalism; and (IX) disease prevention, health promotion, and public health. Conclusion. The research strategy extends to and complements the prevailing hierarchical system by introducing a broad "evidence house" approach to evaluation, something many health technology assessment boards today support. It may provide transparent and comprehensive insight into potential benefits or risks of AM. It can serve as a framework for an evidence-informed approach to AM for a variety of stakeholders and collaborating networks with the aim of improving global health.

\section{Background}

Traditional and complementary medicine (T\&CM) is broadly and increasingly used around the world [1]. The wide use is related to cultural aspects and health belief models and to the needs of patients for "whole person care." T\&CM has a strong focus in health maintenance and disease prevention but is also frequently applied for chronic noncommunicable diseases (NCDs). Former WHO general director Margret Chan regarded T\&CM as an oftenunderestimated part of health services, particularly with regard to addressing the challenges of chronic NCDs [1-3] that reach epidemic proportions worldwide, accounting for two-thirds of all deaths. Chronic NCDs have a huge economic impact and lead to high morbidity and disability $[4,5]$. Risk factors are mainly lifestyle-related [6] and are associated with the increasing globalization. To address this enormous health challenge, a wider perspective may be sensible: an integration of successful health-supporting strategies and treatments from conventional medicine and T\&CM, embedded in transcultural understanding and collaboration. This could increase the number of effective approaches, implement them in culturally related health strategies, and target them to the personal values, needs, and resources of the highly heterogeneous populations of patients. As an example, India is mitigating the disease burden of NCDs by launching a National Health program that includes AYUSH systems [7].

The basis for such integrated endeavors is transparency of efficacy, effectiveness, safety, ethics, economics, and understandability of the healthcare strategies, which are the goals of evidence-based healthcare (EBHC): decision-making should be based on evidence, clinical expertise, and patients' values [8-10]. In pursuit of this goal, the development of new health technologies is driven by systematic research. Medicine, however, consists of many interventions, procedures, and treatment systems that have existed since long before the principles of EBHC were introduced. This applies not only to surgical, pharmacological, and nonpharmacological interventions and general care principles, but also to T\&CM (traditional Chinese medicine and Ayurveda, for instance, have existed for thousands of years); self-help approaches (like teas, baths, and wraps); healthy and disease-preventive lifestyles; and integrative medicine (IM) overall.

IM is an umbrella concept, still being developed for the modern and evidence-informed integration of traditional, natural, mind-body, and complementary treatments with conventional medicine. IM systems share the following characteristics: emphasis on salutogenesis, the "natural healing power" of the organism; a holistic understanding of the human being, incorporating physical, mental, emotional, spiritual, and social issues; a focus on lifestyle modifications; extensive use of nonpharmacological interventions; strong emphasis on the therapeutic relationship between practitioner and patient; shared clinical decision-making supported by evidence; and the use of both conventional and complementary treatments $[11,12]$. T\&CM or IM systems comprise whole healthcare systems that have a distinct, unique perspective on nature, the human organism, and disease and derive their therapies accordingly [13]. Some $\mathrm{T} \& \mathrm{CM}$ interventions have received wide attention in medicine, e.g., Artemisia annua (Nobel Prize 2015 [14]), mind-body medicine techniques like meditation [15], yoga $[16,17]$, acupuncture [18], and many modern medicines derived from natural products that were first used in a traditional medicine context [1-3].

T\&CM methods are broadly investigated, further developed, tested, and verified using scientific methods $[2,3,18-20]$ that are supported by research networks (e.g., WHO, CAMbrella, NCCIH, SIO, ISCMR, ACIMH) [1, 21-28]. The Cochrane library lists more than 460 Cochrane reviews and more than 26,000 randomized controlled trials (RCTs) on T\&CM [29]. These often mimic conventional mono-drug research investigating specific efficacy with explanatory placebo-controlled RCTs. However, given the specific challenges of investigating complex therapies as well as patient-centered care, there is currently a shift toward pragmatic research targeting comparative effectiveness of interventions as they are practiced in real-life situations. Furthermore, the importance of patients' subjective experiences is increasingly recognized as accountable and as necessary measures in health intervention evaluations. Also patient's healthy resources and values are seen as essential to promote a healthy lifestyle, reduce risk factors, and support compliance. These considerations lead to an increased use of qualitative research to explore patients' views and needs. They also lead to the construction of questionnaires that assess dimensions of health care that are of real concern for patients. A mixed-methods approach is pursued to gather information from multiple sources $[1,9,21-28,30-35]$.

Anthroposophic Medicine (AM) is one of the whole healthcare systems of IM [36]. It is based on a holistic, 
system-oriented understanding of man and nature, including disease and treatment. Its organismic concept consists of four levels (physical organization, life processes, soul, and spirit) and three constitutional systems (nervesense, metabolic-limb, rhythmic). AM is embedded in countrywide care systems, secondary and tertiary care hospitals, primary health centers, and private medical practices [36]. It applies medicines derived from plants, minerals, and animals; nursing procedures like rhythmical embrocations, baths, and wraps; arts therapies like music, painting, and sculpture; movement (eurythmy) therapy; physiotherapies such as rhythmical massage; lifestyle recommendations associated to AM philosophy concerning nutrition, agriculture, education; and meditation and mindfulness, psycho-spiritual counseling, and psychosocial support. AM care is provided by certified medical doctors, nurses, therapists, midwives, psychotherapists, and nutritionists [36-38]. AM education is provided by specific schools, universities, and other academic institutions [36].

AM has been widely investigated $[36,39,40]$; however, additional research activities are needed: owing to the goals of EBHC; for research-driven innovation and development in AM therapies and strategies; and to assess whether certain AM approaches can contribute to the management of significant healthcare problems, particularly chronic NCDs. These approaches include specific treatments such as certain nursing applications (to treat, for instance, insomnia, anxiety, chronic pain, osteoarthritis) [41, 42]; herbal extracts (e.g., for skin diseases, cancer, maternity care, and atopic diseases) [43, 44]; and eurythmy therapy (e.g., for chronic pain, mental conditions, high risk of falling among the elderly) [45]. They also include multimodal concepts (e.g., for fatigue and other quality-of-life issues in chronic NCDs and chronic infections) [46, 47]; models of patient-centered care (e.g., for pediatric diabetic care or depressive disorder) [48-50]; community care (e.g., for chronic pain with associated multimorbidity) [51]; strategies for dealing with fever (http://warmuptofever.org/en/) [52]; prevention strategies (for atopic diseases and allergies) [53, 54]; and support of self-efficacy [55] and perspectives on both the patient's and the care provider's needs [56, 57].

The investigation of a whole healthcare system like AM [13] entails a number of specific challenges:

(i) The patient-centered vs disease-centered approach, which is a hallmark of AM with its strong focus on individual resources of the patients and their psychological, biographical, and spiritual needs, and on shared decision-making and support of self-efficacy. This approach shifts the focus from study methods that assess effectiveness of therapies for average patients sharing a particular diagnosis; rather, it addresses the question of whether the therapy is effective for this individual patient with (potentially) several diagnoses (in theory, highly individualized patient-centered care can be tested as a black box in pragmatic comparative trials, but these trials, in addition to their exceeding complexity, lose explanatory power, transparency, and transferability of the results) [58].

(ii) The multimodal approach, applying several interventions (including conventional and other T\&CM methods) in the same patient, depending on the condition. This addresses the complexity of chronic NCDs in particular and the frequent concomitant diseases.

(iii) The large diversity of treatments: about 1000 medicinal products and medicinally used natural substances [59], as well as therapeutic approaches like nursing approaches, arts or movement therapies, and counseling. This by far exceeds the singlecomponent efficacy testing with one or two clinical trials each.

(iv) The limited number of patients "fitting into" the trials while accepting a standardized care allocated randomly and who are not already recruited by competing trials [60-62]. Also, the limited acceptance of randomization by AM care providers [62] restricts the conductibility of large trials.

(v) The high costs of trials (confirmatory drug trials costing 11-53 million US\$, on average [63]) and sparse funding possibilities (commercial interest restricted to a few remedies, rare public funding, most research being supported by foundations, philanthropic engagement or personal commitment of researchers). This necessitates an efficient use of resources.

(vi) AM care is often perceived as a therapeutic process, a "healing journey" shared by patient and practitioners stemming from a spiritual "commitment" [64] and not to be disturbed by a clinical trial design. Specifically, as these "joined healing journeys" may reveal perspectives for addressing unmet needs of severely ill patients $[65,66]$, evaluation designs should preserve or even uncover preferences, individualization and intercultural experience, and potential effects related to practitioner-patient communication and rapport.

Given this complex situation and the challenges it presents, a strategic framework is sensible to test efficacy, effectiveness, and the cost-benefit ratio; to ensure safety and ethical principles as well as real-life application; to provide transparency and explore patients' needs, views, experiences, and the public's interest; and to contribute potential solutions for health challenges such as chronic NCDs. To develop this research strategy, a consensus process was chosen in order to incorporate different views, expertise, and resources.

\section{Development of a Consensus-Based Research Strategy: Methodology}

In developing the research strategy, we pursued a threephase consensus process adapted to the Guidance for 
Developers of Health Research Reporting Guidelines [67, 68]: This consisted of (1) premeeting literature reviews, firstly on recommendations for investigating whole healthcare systems, and secondly on which objectives, to what extent, have been investigated on AM up to now; this was followed by interviews with key stakeholders to supplement or revise items of the research strategy, to include rationale and supporting references, and to tailor the strategy to AM research; (2) face-to-face consensus meetings for further developing and tailoring the strategy; and (3) postmeeting feedback followed by finalization.

2.1. Phase I. Key items of the strategy were developed from first literature review. They were presented to, discussed with, and supplemented by 162 key stakeholders in the field who fulfilled at least one of the following criteria: members of AM research council; representatives of $\mathrm{AM}$ at academic institutions, AM physicians, or members of patients associations; researchers in the field with different expertise; AM nursing and nursing scientists; arts therapists; representatives of AM supporting foundations; pharmacists (including AMrelated pharma executives and research or medical directors); AM contact persons for regulatory agencies; and medical educators (including lecturers with university academic appointments). Stakeholders included healthcare practitioners employed in a conventional non-AM medical setting, and medical directors of units/departments within a conventional setting where AM is being newly implemented. Countries represented were Germany, Italy, Switzerland, Great Britain, Hungary, Sweden, Slovenia, Spain, South Korea, Netherlands, Israel, Russia, USA, Brazil, Chile, Peru, Argentina, and India.

2.2. Phase 2. The face-to-face consensus meeting at the International Research Council in Dornach, Switzerland (September 2017), included 25 participants. The meeting began with a review and discussion of the recommendations elicited during the literature review and interviews of Phase 1. These recommendations were clarified, further justified, modified, or new details were added. Additionally, the strategy was presented and discussed at two conferences in Filderstadt, Germany (May 2017), and Dornach, Switzerland (March 2018), including 45 and 107 international experts on AM research and practice, respectively.

2.3. Phase 3. The draft strategy was refined and sent for review to the AM Research Strategy Group $(n=48)$. The finalized strategy incorporated the feedback from this group.

\section{Results: An Integrative Research Strategy}

Just as AM covers many fields in healthcare, nearly all medical specialties, in different settings (outpatient, inpatient; primary, secondary, tertiary care; private practice or within the public health insurance system; acute and chronic conditions; medical prevention; health education and pedagogy) with the help of a wide variety of healthcare providers and training specialties, the field of active research is widespread.

Therefore, an integrative evaluation strategy is seen as sensible and has already been implicitly pursued. A reasonable amount of methodologically rigorous confirmatory RCTs on exemplary therapies and indications should be conducted. However, the majority of interventions should be assessed in system evaluations and smaller studies. Research on biomedical, physiological, pharmacological, psychological, anthropological, and nosological issues provides insight into treatment and care processes and also into patients' perspectives, goals, and achievements. The different sources of information around this strategy address individual interventions and also the complexity, different core aspects, and challenges of the whole healthcare system and the patientcentered approach. Loss of important information using only one design is minimized, as the specific focus and strength of each design complement those of others. Thus, by merging different designs and results, a comprehensive "evidence house" will be possible, with different parts serving as pieces of a puzzle to complete a whole picture.

The strategy could be a framework for

(i) Researchers investigating AM and T\&CM, assessing or discussing AM, collaborating internationally

(ii) Care providers participating in, supporting, informing, or presenting research

(iii) The medical community in general, professional organizations, medical directors for information, transparency, dialogue, and decision-making

(iv) Authorities, regulating AM

(v) Health policy and prevention policies implementing research results

(vi) Private and public funders, pharmaceutical companies funding research

(vii) Patients and their relatives and representatives, advocacy groups

(viii) Students and educational organizations (e.g., universities) with interest in T\&CM

(ix) The public, civil organizations, via public relations and journalism

The methodological aspects of the strategy are outlined in the following section, supplemented by examples of previous and current AM research. The details are exemplary and will have to be adapted based on resources, research results, research methods, quality standards and administrative requirements, healthcare issues and health policy, funding policies, and the resources and interests of researchers.

The strategy refers to the research on (I) efficacy/effectiveness; (II) safety; (III) economics; (IV) evidence synthesis; (V) methodological issues; (VI) biomedical, physiological, pharmacological, pharmaceutical, psychological, anthropological, and nosological issues as well as innovation and development; (VII) patient perspective and involvement, public needs, and ethics; (VIII) educational matters and professionalism; and (IX) disease prevention, health promotion, and public health. 


\subsection{Efficacy/Effectiveness}

3.1.1. Evaluation of the Multidisciplinary Health System as a Whole, or of Complex Multimodal Therapy Concepts. A system evaluation, rather than assessing a specific remedy or treatment modality, approaches the entire complex, multidisciplinary, and multimodal treatment procedure. It is a "black box" approach to the whole treatment system or to specific multimodal therapy concepts and does not primarily differentiate the effects of the singular interventional elements. System evaluation studies assess several interventions that are simultaneously applied (for instance [46]) and/or individually tailored (for instance $[62,69,70]$ ). These studies can investigate established multimodal AM treatment concepts for relevant conditions (like rheumatoid arthritis [71] or cancer-related fatigue [46]) applied across all patients, and individually adapted to meet the patients' strengths and limitations. Outcomes can be disease-specific or more general PROMs (e.g., health-related quality of life) or patient-generated (e.g., MYMOP [72]). Such studies can also investigate the whole system of AM, for instance in patients with one or more chronic conditions (e.g., $[69,70,73])$, but also with acute diseases (e.g., [62]), diagnosed, treated, and counseled within the AM understanding of man and nature. Hereby, the healthcare providers' diagnostic and therapeutic abilities are also a major part of the "black box." Depending on the conditions included, possible outcomes can be more generic, like a disease score or survival (e.g., in cancer), or patient-generated, or health-related quality of life, but also diseasespecific outcomes in subgroups with a specific condition (as in the Anthroposophic Medicine Outcome Study, AMOS $[69,70])$. These studies can also investigate certain care models, particularly for chronic diseases (e.g., depression [50] or community care models [51]), or specific patientcentered care models (like patient-centered diabetic care $[48,49])$. The evaluation methods acknowledge the multilevel nature of many diseases and the individual presentation of diseases in most patients and the necessity for a multimodal and individualized therapeutic approach $[1,9,21-28,30-34,74]$. For such evaluations, different study designs can be chosen depending on the patient groups, interventions, controls, and contexts: comparative effectiveness studies, observational research (potentially using a bias suppression analysis or systematic outcome comparison as used in AMOS $[75,76])$, experimental designs, pragmatic trials [69, 70], preference-based trials, quasiexperimental designs (using for instance interrupted time-series, instrumental variable analysis, regression discontinuity analyses, as reviewed in $[77,78]$ ), or health services research [79]. In several of these designs, also matched-pair comparisons, synthetic controls and other regression techniques can be applied.

These evaluations require a good deal of methodological competence, knowledge, experience, and collaboration. Detailed a priori planning in this field is limited as it depends on the individual researcher and on opportunities to conduct such studies and available funding. A prespecified plan for the analysis and public protocol registration is strongly encouraged, whenever possible, using common databases such as ClinicalTrials.gov.

3.1.2. Exemplary Interventions in Certain Indications: Confirmative Randomized Clinical Trials. A variety of specific AM interventions are well established and widely regarded as beneficial in certain health conditions. They may also support, independently from the AM treatment context, the effective treatment of major healthcare conditions (e.g., allergies, skin diseases, reducing nonindicated antibiotic prescriptions and resistance, chronic pain, mental diseases, risk of falling in elderly, and other chronic NCDs). The efficacy, safety, and efficiency of exemplary interventions should be investigated in a reasonable and feasible number of sufficiently powered confirmatory RCTs, with the potential goal of the interventions being implemented in treatment guidelines.

To be worthwhile for an investigation in confirmative RCTs, interventions need to meet certain conditions: they have to have a rationale for the improvement of a relevant health condition. This should be supported by good empirical data from clinical, physiological, or exploratory studies, in order to design the trial, define outcomes, follow-up periods, control intervention, and calculate the sample size. This also refers to issues of application form, dosage, and duration. They should be applied in a health condition with a need for further interventions, e.g., when standard interventions have limited efficacy, are not well accepted by patients, or are better accepted with a cointervention (e.g., mistletoe extracts in cancer or cancer-related symptoms [80, 81], NCT02948309, NCT02106572); dermatology [44]; eurythmy therapy in cases of high risk of falling (DRKS00016609); and nursing procedures in pain, obstipation, nausea, sleep disturbance, anxiety, and others [82, 83]). Confirmative RCTs are often large, conducted in multicenter settings, as a collaborative effort of experts in different fields (including patient representatives) and guided by various guidelines, standards, and national requirements. These trials are very expensive and require appropriate funding and clinical infrastructure, both of which are in relatively short supply in AM.

3.1.3. The Wide Range of Remaining Interventions and Patient-Centered Care Strategies: Well-Conducted Small Trials and Observational Studies, High-Quality Case Reports and Series, Subgroup Analyses from Whole-System Studies, and Health Service Research. The large quantity of AM interventions and their use within a patient-centered approach (about 1000 medicines, but also nursing procedures, arts therapies, eurythmy therapy, massages, embrocation, packs, teas, dietary advice, lifestyle counseling, therapeutic talks regarding emotional, biographical, social, and spiritual issues, and educational methods) exceed the current capacity to assess these interventions in large confirmative trials. Therefore, the majority of interventions should be (and have been) investigated or transparently presented, partly in 
smaller formats but still with high methodological quality: for instance, observational studies and small clinical trials; case series and case reports; subanalyses from large studies $[70,84]$; matched-pair comparisons (AM vs not AM-treated patients); health service research (e.g., clinical registries); or research syntheses from other similar interventions (e.g., non-AM Arnica preparation). Many methodological elements described above for the evaluation of health systems can also be applied.

Altogether, many of these methods, supported by quality standards and guidelines, are less demanding, complex, and costly and can be conducted as smaller research projects. Every effort has to be done to enhance quality and transparency and reduce the risk of bias. Still, these designs will often not provide causal evidence and are frequently subject to bias. These studies will often make use of "real-life data," with the primary focus sometimes switching to the point of care, providing insights into therapeutic procedures like patient-centered care [48] or addressing specific, unique conditions. [42, 85] Some of these methods will be influenced by future specific or general developments [86-88].

3.2. Safety. With regard to safety, a variety of objectives and methods can provide information and have been used for investigations in AM: a key source for safety data are adverse events and tolerability assessed within clinical trials and studies. Another, much wider source for safety information is pharmacovigilance studies and health service research $[59,89]$. Many side effects of interventions, also rare ones, are captured with case reports and reports from authorities [39]. Vulnerable populations, like pregnant women, children, or elderly, need particular attention and research-in clinical trials, observational or pharmacovigilance studies, or specific registries. Specific safety issues (e.g., pharmacological interaction of AM-drugs with conventional drugs or with other AM or T\&CM drugs [90-92]) may need a focused investigation using different methodologies.

Besides these classic assessments of untoward effects of interventions, also other safety issues are related to the whole field of T\&CM as well as AM and can be investigated with different methodologies: for instance the impact of AM on patients' adherence to conventional medicine treatments (e.g., compliance with scheduled chemotherapy protocol [93]) and associated treatment effectiveness or the impact of AM on decreasing unjustified overuse of conventional drugs (nonindicated antibiotics prescriptions, analgesics overuse, etc. $[51,62,94,95])$, to reduce drug-associated adverse effects, morbidity, and health costs [59, 71, 96-98]. A further safety issue necessitating also exploratory research relates to patients who adopt "alternative" health belief models that they (wrongly) associate with AM, expressed by negation of evidence-based conventional treatments or prevention recommendations (e.g., certain vaccinations, antibiotics, chemotherapy, steroids).

For the various methods, standards and guidelines exist or have to be adapted. A large body of evidence is available $[36,39,59]$ and cooperation with national drug agencies established.
3.3. Economics. The economic implications of therapeutic strategies should be evaluated [96-98]. Direct, indirect, and intangible costs have to be considered, as well as different perspectives (e.g., societal, patient, and health insurance), depending on the setting. Different evaluation techniques are available (e.g., cost-effectiveness analysis, cost-utility analysis, and cost-benefit analysis), cost-effectiveness analysis being the most common. RCTs should consider collecting cost data (e.g., inpatient care, outpatient care, etc.) and standardized quality-of-life metrics to allow an estimate of quality-adjusted life-years (QALYs). Real-life data (registries) can be used as well in context with good quality records. The extent of the evaluations should be such to capture all relevant differences regarding outcomes between the intervention and comparators; therefore, lifetime horizons using decision-analytic models are preferred [99-101]. Adopting Good Research Practices from ISPOR is highly recommended (http://www.ispor.org). Reporting of economic evaluations of AM should follow the standard Consolidated Health Economic Evaluation Reporting Standards (CHEERS) [102].

\subsection{Evidence Synthesis, Systematic Reviews, and HTA Reports.} The results of efficacy and effectiveness research and of safety and economic evaluations have to be systematically collected, reviewed, and assessed in their methodological quality and analyzed across individual studies. This applies to both single interventions on certain conditions and complex, multimodal or individualized therapeutic systems. The goal would be that the strengths of and specific information gleaned from the different designs and studies complement each other so that the compiled data and results form a reasonable, informative, and transparent evidence house (which should then also include points 3.5.-3.7.). Modeling studies can be helpful in estimating the public health benefit and costs of AM based on data from primary or secondary sources to inform decisions on healthcare policy [103].

For clinical trials and observational studies, the methodology of systematic reviews and meta-analyses has been developed, and widely used methods as proposed by Cochrane and GRADE are available (http://www.cochrane. org). For other assessment designs, complex, integrative intervention models, case reports, etc., meta-methods like mixed-methods reviews, critical appraisal, and evidencemapping remain to be fully considered or further developed. On a broader perspective, HTA reports can be useful $[39,40,104]$.

3.5. Methodologic Issues. For many research designs, methods and standards have been developed, and guidelines are available to ensure quality and to define the applicability and generalizability of the results. For other designs, such as analyses and subanalyses, these methods have to be further developed. This concept relates specifically, for instance, to "whole system" and "complex intervention" research; bias reduction and systematic outcome comparison in large observational studies $[75,76]$; case reports $[105,106]$ and 
their use (e.g., applicability, strengths, weaknesses, generalizability, causality, [107-109]) and their systematic assessment; health service research, care models, and issues related to clinical judgment and expertise [110], clinical decision analysis, individualizing and patterning of clinical responses [107, 108, 111], and "process-oriented research" [112].

The development of methods is carried out in close cooperation and consensus procedures with competent epidemiologists, statisticians, economists, methodologists, clinical researchers, and healthcare experts in related fields. An ongoing dialogue with decision makers, health professional organizations, and journal editors helps to incorporate their views and interests.

3.6. Biomedical, Physiological, Pharmacological, Pharmaceutical, Psychological, Anthropological, and Nosological Issues, as well as Innovation and Development. Research should unravel the working principles of the interventions, contribute to the transparency of the AM concepts of the human organism and of health and disease, relate these to other medical and scientific concepts, and further develop medical and healthcare strategies. This relates to AM remedies, to understand their molecular, epigenetic, cellular, biochemical, physiological, pathophysiological, immunological, neurological, psycho-neuro-immunological mechanisms involved, the social context, etc. $[43,113,114]$. The same accounts to nonpharmacological interventions, lifestyle changes, or counseling: do they have effects on physiological rhythms, epigenetics, the psychosocial level, or on individual mental-cognitive developmental processes? A key issue is specifics of dosage and application and other pharmacological questions as well as issues of pharmaceutical quality. As AM has a distinct and hierarchical concept of the human organism that extends into nosological and diagnostic categories, these diagnostic (practice) methods, for instance, the constitution types of AM, have to be further elaborated and validated. This also includes the development and validation of questionnaires in different fields $[115,116]$. Altogether, the anthroposophic-anthropologic concept of the human being, nature, health, and disease (salutogenesis) and therapy is a large field for epistemological, conceptual, and experimental research. This includes the concepts of human beings as social individuals (bio-psycho-socialspiritual approach), of organisms as complex adaptive systems, and of emergent behavior [117-119]. Also, AM nursing models and concepts, widely established in practice, can be further investigated. Last not least, these fields connect to innovations and further development of interventions within AM health care $[82,83,114]$.

3.7. Patient Perspective and Involvement, Public Need, and Ethics. The view from the goal-investigating patients' perspectives using AM healthcare systems or specific AM interventions, and involving patients in research-provides important information and is a key area in the research field today: patient and public needs, interests, and perspectives on AM are assessed by qualitative and questionnaire-based methods and systematic metaethnographic approaches [120-122]. For clinical research, patient-relevant and experience measurements are developed (PROMS and PREMS) [123]. First-person perspective studies, including biographic introspection, can give important insight in understanding the subjective dimension of disease. Patients are increasingly involved in the development of study designs and priority-setting (see http://www.invo.org.uk), also in AM (e.g., ENTAIER trial, DRKS00016609), which is another field of further development. Patient involvement and research also focuses on the development, evaluation, and implementation of patient empowerment, patient information, and decision-making material, as well as self-care programs using AM [49, 124, 125]. Another large field refers to the elements of ethics in AM healthcare professions and in applications of AM interventions in and outside AM and to contributions to the general ethics discussion. This includes general topics of medical ethics but also the important issue of informed consent, particularly with regard to missing evidence or to lacks in safety data, and the issue on how to deal with interventions or recommendations, which lack robust evaluation.

3.8. Educational Matters and Professionalism. Educational research provides important insights into the clinical trainings of healthcare professionals, the quality and issues of medical training, and the AM education, including medical students' possible contributions to patient-centered care [126, 127]. Furthermore, integration of AM (or parts of it) into established healthcare systems could be outlined and investigated, and the impact of AM courses on medical students' perspectives in pregraduate and postgraduate settings could be evaluated [128, 129]; furthermore, the impact of integrative medicine training on a mixed AM and non-AM group of practitioners, preferably in a multidisciplinary context, could be evaluated [130], as well as the influence of stress on burnout symptoms and empathy of care providers and their spiritual needs $[57,131]$. Criteria for professionalism specific to AM or T\&CM physicians [132] could be further adapted for all health professions.

3.9. Disease Prevention, Health Promotion, and Public Health. AM healthcare aims to understand and support the whole human being. Therefore, in addition to treating illnesses and symptoms, healthy development is supported during the entire lifetime (i.e., before, during, and after birth; during childhood, adolescence, adulthood, and end-of-life) and also during the development of emotional, cognitive, and spiritual competencies. A positive health concept is the goal [133]. Interdisciplinary work is pivotal and also includes consideration of pedagogy and agriculture and environmental aspects. Research in these areas will depend on research collaboration and networking on a large scale, including collaboration with, for instance, epidemiologists, healthcare insurers, and public health institutions. $[53,54,134]$. 


\section{Discussion}

This research strategy covers the large spectrum of a whole healthcare system. It encompasses an array of experimental and explanatory to observational and pragmatic designs, from preventive to palliative care, from intervention to the patient's perspective, from inpatient to outpatient care. The fields of basic and conceptual research and innovation also are a part to this strategy but are only roughly outlined. The strategy is based on the following: existing methodological discussion of investigating whole medical and healthcare systems including complex interventions [1, 9, 21-28, 30-34]; what is regarded as important by key stakeholders; and what research is actually currently pursued or planned. Future developments may further evolve and refine this strategy.

This strategy can provide a broad view of the different aspects of the whole medical and healthcare system of AM and can also support the development of specific interventions or healthcare concepts that may be relevant for healthcare in general. It also provides insight about patients' perspectives and needs and with regard to issues of education and professionalism. It offers a framework for different stakeholders in medicine, science, and the general public, and it may improve intercultural transparency. The pluralistic and integrative nature of the presented strategy portends that the whole body of results will present a more adequate perspective of the complex field of AM than the isolated parts would have.

The scope of the strategy does not specify the fields actually being the focus of research. We presume that managing and treating chronic NCDs and focusing on disease prevention will be of primary interest. Still, the actual focus depends on the individual researchers and clinicians; their institutions' interests, capabilities, and infrastructures; the related collaboration and networks; the potential benefit expected with the specific intervention under investigation; and also on public interest and the priority-setting of funders.

Four leading obstacles impede the promotion of AM research with high-quality methodology.

4.1. External Factors. Successful high-quality research will be impeded by budget limitations. However, even large studies are increasingly funded, and therefore an increasing rate of high-quality and clinically significant research will foster trust in AM research. Inclination of the scientific community to embrace explanatory rather than pragmatic trials and RCTs rather than observational and real-life studies will impede the successful conduction, funding, and publication of whole healthcare systems studies. However, there is an increasing interest in a broader spectrum of designs due to the complexity and individualization of medicine [9, 30-34, 86-88], and therefore, high quality of these studies as well as research on methodologic issue will be essential.

4.2. Internal Factors. These relate to a limited number of trained AM researchers and healthcare settings as well as to potential reluctance of some AM clinicians and healthcare providers to conduct, support, and participate in clinical research due to workload, skepticism about research, standardized care, and randomized treatment allocation that conflicts with the individualized, patient-centered approach they would like to employ. Close collaboration, consideration of clinicians' and healthcare providers' needs and constraints, and communication about the benefits and risks of research (e.g., presenting research projects and results at AM practitioners' conferences and integrating AM clinicians, healthcare providers, and patients in research planning and study design) may help to overcome these limitations. Still, a variety of research studies, specifically experimental, highly standardized designs like RCTs on a specific treatment in a certain disease, will have to be conducted outside the AM setting (e.g., NCT02948309 and NCT02106572).

4.3. Methodologic Factors. While for RCTs a variety of guidelines, standards, and requirements are well defined, other study types may have less rigor and less demanding quality criteria and guidelines. Therefore, quality and scrutiny parameters in planning, design, data quality, analysis, presentation, careful inferences, and general standards of good clinical research have to be strictly followed [135-137]. Commitment by researchers and review by ethical committees, funders, and journals still might not ensure high quality. Therefore, the development of further specific methodological-quality guidelines for researchers and funders and later assessments, as well as specific training, additional internal and external peer review, discussion within the broader network already in the planning phase, and continuous methodological dialogue and awards for high-quality projects, may support and improve this approach long-term. Furthermore, the assessments of such an area of integrative research studies, for instance with HTA reports, may become elaborate. This may necessitate further methodological developments to improve pragmatic and efficient meta-assessments.

The strength of this consensus-based strategy is the consideration of different dimensions of a healthcare system, the inclusion of a large variety of stakeholders like care providers, MDs from in and outpatient care with different specialties, directors of institutions or hospitals, pharmacists, patient representatives, funding bodies, and researchers with diverse expertise and intercultural aspects. Thus, the input is based on specific scientific knowledge as well as long practical experience with patient care, research projects, and extensive collaboration.

Still, this consensus strategy also has some limitations. It is a current view and does not foresee future developments, researchers, and stakeholders, which may modify some items of the strategy. It also does not foresee the availability of resources and funding. Therefore, the strategy is a matter of estimation and intention. Although the consensus process includes many, it does not include all relevant stakeholders outside AM, like public funders, journal editors, researchers conducting future systematic reviews and HTA reports on 
$\mathrm{AM}$ or investigating other whole healthcare systems, and authorities. However, the included stakeholders have multiple collaborations with these "external" stakeholders.

In conclusion, this strategy provides a wide spectrum of research that will assess many facets of a whole healthcare system pursuing patient-centered care. This may contribute to solutions for global health challenges, particularly with regard to chronic NCDs and health promotion. The culture of collaboration with other IM and non-IM methodologists and researchers is of great importance and value. Researchers investigating other integrative modalities such as traditional Chinese and Ayurvedic medicine as well as researchers investigating patient-centered care and patienttailored treatment (e,g. Family medicine, palliative medicine, narrative-based medicine, and psycho-social-ethno literature, spiritual care research) are confronted with some or all of the challenges described in this article. Interdisciplinary and international collaboration effect more expertise and infrastructure for high-quality research projects. Furthermore, collaboration with other stakeholders in the healthcare system, at academic institutions, at professional and patient organizations, with associations and committees involved in guideline development and healthcare planning, research, and funding, will assist with purposeful, efficient, and high-quality research development.

\section{Conclusion}

T\&CM, used worldwide and integrated into EBHC, can play an important part in health services, supporting health, and addressing chronic NCDs. Its focus is on patient-centered care, and it is linked to the cultural background and needs and values of patients. Transparency and information are provided by a strong and differentiated evidence base regarding benefit and implementation of T\&CM approaches, assessing efficacy, effectiveness, safety, costs, modes of action, patient and public perspective, ethical issues, educational matters, professionalism, and healthcare procedures and concepts. A broad research strategy, as outlined for Anthroposophic Medicine, supports research and healthcare, transcultural understanding, and collaboration among different stakeholders of healthcare.

\section{Abbreviations}

ABHC: $\quad$ Evidence-based healthcare

ACIMH: Academic Consortium for Integrative

Medicine and Health

AM: $\quad$ Anthroposophic Medicine

AMOS: Anthroposophic Medicine Outcome Study

CAMbrella: European research network for complementary and alternative medicine

CHEERS: Consolidated Health Economic Evaluation Reporting Standards

ENTAiER Randomized controlled trial on efficacy and trial: $\quad$ safety of Eurythmy Therapy and Tai Chi in chronically ill elderly patients with high risk of falling
HTA: Health Technology Assessment

IM: Integrative Medicine

ISPOR: International Society for Pharmacoeconomics and Outcomes Research

ISCMR: International Society for Complementary Medicine Research

MYMOP: Measure Yourself Medical Outcome Profile

NCCIH: National Center for Complementary and Integrative Health

NCDs: $\quad$ Noncommunicable diseases

NCT: $\quad$ ClinicalTrials.gov registry number

PREMS: $\quad$ Patient reported experience measures

PROMS: $\quad$ Patient reported outcome measures

RCTs: $\quad$ Randomized controlled trials

SIO: $\quad$ Society for Integrative Oncology

T\&CM: Traditional and complementary medicine

WHO: World Health Organization.

\section{Data Availability}

The data are available from the public databases (e.g., PubMed/MEDLINE) or are available from corresponding author on reasonable request.

\section{Disclosure}

The entire AM Research Strategy Group participated in parts or all of the strategy development process and contributed to the editing and revision of the article.

\section{Conflicts of Interest}

The authors declare that they have no conflicts of interest.

\section{Authors' Contributions}

GSK wrote the first draft of the article. EBA, BB, CCN, TF, KG, HK, DM, UW, and HS critically reviewed and edited drafts.

\section{Acknowledgments}

We are grateful for the participation in the AM Research Strategy Group to Erik Baars, Ricardo R. Bartelme, Eran Ben-Arye, Iracema Benevides, Bettina Berger, Thomas Breitkreuz, Arndt Büssing, Christoph von Dach, Torkel Falkenberg, Gabor Kapócs, Stefan Geider, Ricardo Ghelman, Matthias Girke, Harald Gruber, Harald Hamre, Peter Heusser, Benedikt Huber, Roman Huber, Steven M. Johnson, Helmut Kiene, Gunver Kienle, Denis Koshechkin, Klaus Kramer, Matthias Kröz, Daniel Krüerke, Alicia LandmanReiner, Alfred Längler, Gero Leneweit, David Martin, Harald Matthes, Harihara Murthy, Cristobal Cuadrado Nahum, Srinivasa Rao Nyapati, Emanuela Portalupi, Ravi M Doctor, Friedemann Schad, Christian Scheffer, Christoph Schempp, Marc Schlaeppi, Stefan Schmidt-Troschke, Tido von Schoen-Angerer, Ana Paula Simões-Wüst, Georg Soldner, Henrik Szöke, Jan Vagedes, Yván Villegas, Paul Werthmann, and Ursula Wolf. This is an investigator-initiated project that was performed without extra funding. The 
authors owe sincere thanks to all stakeholders participating in the discussion and consensus process.

\section{References}

[1] World Health Organization, WHO Traditional Medicine Strategy: 2014-2023, World Health Organization, Geneva, Switzerland, 2013.

[2] T. P. Fan, J. Briggs, L. Liu, A. Lu, J. van der Greef, and A. Xu, "The art and science of traditional medicine part 2: multidisciplinary approaches for studying traditional medicine," Science, vol. 347, no. 6219, p. 337, 2015.

[3] S. Sanders, T. P. Fan, J. Briggs et al., "The art and science of traditional medicine part 1: TCM today-a case for integration," Science, vol. 346, pp. S1-S25, 2014.

[4] A. S. Daar, P. A. Singer, D. Leah Persad et al., "Grand challenges in chronic non-communicable diseases," Nature, vol. 450, no. 7169, pp. 494-496, 2007.

[5] R. Lozano, M. Naghavi, K. Foreman et al., "Global and regional mortality from 235 causes of death for 20 age groups in 1990 and 2010: a systematic analysis for the Global Burden of Disease Study 2010," Lancet, vol. 380, pp. 2095-2128, 2012.

[6] R. Beaglehole, R. Bonita, R. Horton et al., "Priority actions for the non-communicable disease crisis," The Lancet, vol. 377, no. 9775, pp. 1438-1447, 2011.

[7] Press Information Bureau, Government of India, "Shri Shripad Naik Launches Pilot Project 'Integration of Homoeopathy/Yoga with NPCDCS in Krishna District' at Gudivada in Andhra Pradesh," February 2016, http://pib.nic. in/newsite/PrintRelease. aspx?relid=136466.

[8] D. L. Sackett, W. M. C. Rosenberg, J. A. M. Gray, R. B. Haynes, and W. S. Richardson, "Evidence based medicine: what it is and what it isn't," $B M J$, vol. 312, no. 7023, pp. 71-72, 1996.

[9] T. Greenhalgh, J. Howick, and N. Maskrey, "Evidence based medicine: a movement in crisis?," $B M J$, vol. 348 , no. 134 , p. g3725, 2014.

[10] C. Heneghan, K. R. Mahtani, B. Goldacre, F. Godlee, H. Macdonald, and D. Jarvies, "Evidence based medicine manifesto for better healthcare,” BMJ, vol. 357, p. j2973, 2017.

[11] http://www.imconsortium.org/about/about-us.cfm, 2018.

[12] D. W. Abrams and Andrew T. Wei, Integrative Oncology, Oxford University Press, Oxford, UK, 2014.

[13] E. W. Baars and H. J. Hamre, "Whole medical systems versus the system of conventional biomedicine: a critical, narrative review of similarities, differences, and factors that promote the integration process," Evidence-Based Complementary and Alternative Medicine, vol. 2017, Article ID 4904930, 13 pages, 2017.

[14] T. Efferth, S. Zacchino, M. I. Georgiev, L. Liu, H. Wagner, and A. Panossian, "Nobel Prize for artemisinin brings phytotherapy into the spotlight," Phytomedicine, vol. 22, no. 13, pp. A1-A3, 2015.

[15] H. Greenlee, L. G. Balneaves, L. E. Carlson et al., “Clinical practice guidelines on the use of integrative therapies as supportive care in patients treated for breast cancer," JNCI Monographs, vol. 2014, no. 50, pp. 346-358, 2014.

[16] H. Cramer, R. Lauche, P. Klose, S. Lange, J. Langhorst, and G. J. Dobos, "Yoga for improving health-related quality of life, mental health and cancer-related symptoms in women diagnosed with breast cancer," Cochrane Database of Systematic Reviews, vol. 1, Article ID CD010802, 2017.
[17] L. S. Wieland, N. Skoetz, K. Pilkington, R. Vempati, C. R. D'Adamo, and B. M. Berman, "Yoga treatment for chronic non-specific low back pain," Cochrane Database of Systematic Reviews, vol. 1, Article ID CD010671, 2017.

[18] B. M. Berman, H. M. Langevin, C. M. Witt, and R. Dubner, "Acupuncture for chronic low back pain," New England Journal of Medicine, vol. 363, no. 5, pp. 454-461, 2010.

[19] K. I. Block, C. Gyllenhaal, L. Lowe et al., "Designing a broadspectrum integrative approach for cancer prevention and treatment," Seminars in Cancer Biology, vol. 35, no. Sl, pp. S276-S304, 2015.

[20] R. Koretz and M. Rotblatt, "Complementary and alternative medicine in gastroenterology: the good, the bad, and the ugly," Clinical Gastroenterology and Hepatology, vol. 2, no. 11, pp. 957-967, 2004.

[21] G. Deng, W. Weber, A. Sood, and K. Kemper, "Integrative medicine research: context and priorities," Explore, vol. 6, no. 3, pp. 143-158, 2009.

[22] H. Boon, H. MacPherson, S. Fleishman et al., "Evaluating complex healthcare systems: a critique of four approaches," Evidence-Based Complementary and Alternative Medicine, vol. 4, no. 3, pp. 279-285, 2007.

[23] H. Walach, T. Falkenberg, V. Fønnebø, G. Lewith, and W. B. Jonas, "Circular instead of hierarchical: methodological principles for the evaluation of complex interventions," BMC Medical Research Methodology, vol. 6, no. $1,2006$.

[24] M. J. Verhoef, G. Lewith, C. Ritenbaugh, H. Boon, S. Fleishman, and A. Leis, "Complementary and alternative medicine whole systems research: beyond identification of inadequacies of the RCT," Complementary Therapies in Medicine, vol. 13, no. 3, pp. 206-212, 2005.

[25] V. Fønnebø, S. Grimsgaard, H. Walach et al., "Researching complementary and alternative treatments-the gatekeepers are not at home," BMC Medical Research Methodology, vol. 7, no. 1, p. 7, 2007.

[26] I. R. Bell, O. Caspi, G. E. R. Schwartz et al., "Integrative medicine and systemic outcomes research," Archives of Internal Medicine, vol. 162, no. 2, pp. 133-140, 2002.

[27] W. Weidenhammer, G. Lewith, T. Falkenberg et al., "EU FP7 project "CAMbrella" to build European research network for complementary and alternative medicine," Research in Complementary Medicine, vol. 18, no. 2, pp. 69-76, 2011.

[28] G. Lewith, W. B. Jonas, and H. Walach, Clinical Research in Complementary Therapies, Churchill Livingstone, Edinburgh, Scotland, 2011.

[29] (("Integrative Medicine") OR "Complementary Medicine") OR Herbal) OR "Traditional Chinese”) OR Acupuncture OR “Taiji” OR “Tai Chi” OR “Qigong” OR "Yoga” OR “Homeopathy" OR "Homeopathic" OR "Natural MEDICINE" OR "Phytotherapy"), August 2018, http://cochranelibrarywiley.com/cochranelibrary/search/.

[30] P. Craig, P. Dieppe, S. Macintyre, S. Michie, I. Nazareth, and M. Petticrew, "Developing and evaluating complex interventions: the new Medical Research Council guidance," BMJ: British Medical Journal, vol. 337, p. a1655, 2008.

[31] M. C. Farquhar, G. Ewing, and S. Booth, "Using mixed methods to develop and evaluate complex interventions in palliative care research," Palliative Medicine, vol. 25, no. 8, pp. 748-757, 2011.

[32] R. Möhler, S. Köpke, and G. Meyer, "Criteria for reporting the development and evaluation of complex interventions in healthcare: revised guideline (CReDECI 2)," Trials, vol. 16, no. 1, p. 204, 2015. 
[33] J.-M. Guise, C. Chang, M. Butler, M. Viswanathan, and P. Tugwell, "AHRQ series on complex intervention systematic reviews-paper 1: an introduction to a series of articles that provide guidance and tools for reviews of complex interventions," Journal of Clinical Epidemiology, vol. 90, pp. 6-10, 2017.

[34] M. Rawlins, "De testimonio: on the evidence for decisions about the use of therapeutic interventions," The Lancet, vol. 372, no. 9656, pp. 2152-2161, 2008.

[35] G. S. Kienle, H.-U. Albonico, L. Fischer et al., "Complementary therapy systems and their integrative evaluation," Explore, vol. 7, no. 3, pp. 175-187, 2011.

[36] G. S. Kienle, H.-U. Albonico, E. Baars, H. J. Hamre, P. Zimmermann, and H. Kiene, "Anthroposophic medicine: an integrative medical system originating in Europe," Global Advances in Health and Medicine, vol. 2, no. 6, pp. 20-31, 2013.

[37] International Federation of Anthroposophic Medical Associations (IVAA), The System of Anthroposophic Medicine, IVAA, Bruxelles, Belgium, 2014, https://www.ivaa.info/fileadmin/editor/ file/The_system_of_Anthroposophic_Medicine_2014.pdf2014.

[38] G. S. Kienle, M. Mussler, D. Fuchs, and H. Kiene, "Individualized integrative cancer care in anthroposophic medicine," Integrative Cancer Therapies, vol. 15, no. 4, pp. 478-494, 2016.

[39] G. S. Kienle, H. Kiene, and H. U. Albonico, Anthroposophic Medicine: Effectiveness, Utility, Costs, Safety, Schattauer Verlag, Stuttgart, Germany, 2006.

[40] G. S. Kienle, A. Glockmann, R. Grugel, H. J. Hamre, and H. Kiene, "Klinische forschung zur anthroposophischen medizin-update eines "Health Technology Assessment»Berichts und Status Quo"," Complementary Medicine Research, vol. 18, no. 5, pp. 269-282, 2011.

[41] T. Therkleson, "Ginger therapy for osteoarthritis: a typical case," Journal of Holistic Nursing, vol. 32, no. 3, pp. 232-239, 2014.

[42] B. Deckers, T. von Schoen-Angerer, B. Voggenreiter, and J. Vagedes, "External nursing applications in the supportive management of prolonged postoperative ileus," Holistic Nursing Practice, vol. 30, no. 4, pp. 216-221, 2016.

[43] U. Wölfle, J. Hoffmann, B. Haarhaus, V. Rao Mittapalli, and C. M. Schempp, "Anti-inflammatory and vasoconstrictive properties of Potentilla erecta-a traditional medicinal plant from the northern hemisphere," Journal of Ethnopharmacology, vol. 204, pp. 86-94, 2017.

[44] A. Schwieger-Briel, D. Kiritsi, C. Schempp, C. Has, and H. Schumann, "Betulin-based oleogel to improve wound healing in dystrophic epidermolysis bullosa: a prospective controlled proof-of-concept study," Dermatology Research and Practice, vol. 2017, Article ID 5068969, 10 pages, 2017.

[45] D. Lötzke, P. Heusser, and A. Büssing, "A systematic literature review on the effectiveness of eurythmy therapy," Journal of Integrative Medicine, vol. 13, no. 4, pp. 217-230, 2015.

[46] M. Kröz, M. Reif, A. Glinz et al., "Impact of a combined multimodal-aerobic and multimodal intervention compared to standard aerobic treatment in breast cancer survivors with chronic cancer-related fatigue - results of a three-armed pragmatic trial in a comprehensive cohort design," $B M C$ Cancer, vol. 17, p. 166, 2017.

[47] H. Szoke, M. Marodi, Z. Sallay, B. Szekely, M. G. Sterner, and G. Hegyi, "Integrative versus conventional therapy of chronic otitis media with effusion and adenoid hypertrophy in children: a prospective observational study," Research in Complementary Medicine, vol. 23, no. 4, pp. 231-239, 2016.
[48] G. S. Kienle, M. Meusers, B. Quecke, and D. Hilgard, "Patient-centered diabetes care in children: an integrated, individualized, systems-oriented, and multidisciplinary approach," Global Advances in Health and Medicine, vol. 2, no. 2, pp. 12-19, 2013.

[49] B. Bartus, D. Hilgard, and M. Meusers, Diabetes und Psychische Auffälligkeiten: Diagnose und Behandlung von Kindern, Jugendlichen und jungen Erwachsenen, Kohlhammer Verlag, Stuttgart, Germany, 2016.

[50] A. S. Ponstein, C. A. Zwart, M. van Gerven, and E. W. Baars, "The development of an anthroposophic, whole medical system, healthcare program for patients with depressive disorders," The Journal of Alternative and Complementary Medicine, vol. 23, no. 12, pp. 941-948, 2017.

[51] E. Wright, R. Zarnegar, I. Hermansen, and D. McGavin, "A clinical evaluation of a community-based rehabilitation and social intervention programme for patients with chronic pain with associated multi-morbidity," Journal of Pain Management, vol. 10, no. 2, pp. 149-159, 2017.

[52] D. D. Martin, "Fever: views in anthroposophic medicine and their scientific validity," Evidence-Based Complementary and Alternative Medicine, vol. 2016, Article ID 3642659, 13 pages, 2016.

[53] J. S. Alm, J. Swartz, G. Lilja, A. Scheynius, and G. Pershagen, "Atopy in children of families with an anthroposophic lifestyle," The Lancet, vol. 353, no. 9163, pp. 1485-1488, 1999.

[54] S. Fagerstedt, H. M. Hesla, E. Ekhager et al., "Anthroposophic lifestyle is associated with a lower incidence of food allergen sensitization in early childhood," Journal of Allergy and Clinical Immunology, vol. 137, no. 4, pp. 1253.e31256.e3, 2016.

[55] B. Berger and P. Heusser, "How to become an agent of one's own healing processes: self-management for chronically ill patients in integrative health care," Complementary Medicine Research, vol. 24, no. 4, pp. 202-204, 2017

[56] A. Büssing, T. Ostermann, and P. F. Matthiessen, "Role of religion and spirituality in medical patients: confirmatory results with the SpREUK questionnaire," Health Qual Life Outcomes, vol. 3, p. 10, 2005.

[57] M. Neumann, F. Edelhäuser, D. Tauschel et al., "Empathy decline and its reasons: a systematic review of studies with medical students and residents," Academic Medicine, vol. 86, no. 8, pp. 996-1009, 2011.

[58] K. E. Thorpe, M. Zwarenstein, A. D. Oxman et al., "A pragmatic-explanatory continuum indicator summary (PRECIS): a tool to help trial designers," Journal of Clinical Epidemiology, vol. 62, no. 5, pp. 464-475, 2009.

[59] H. J. Hamre, A. Glockmann, K. Heckenbach, and H. Matthes, "Use and safety of anthroposophic medicinal products: an analysis of 44,662 patients from the EvaMed pharmacovigilance network," Drugs-Real World Outcomes, vol. 4, no. 4, pp. 199-213, 2017.

[60] E. von Rohr, S. Pampallona, B. van Wegberg et al., "Experiences in the realisation of a research project on anthroposophical medicine in patients with advanced cancer," Schweizer Medizinische Wochenschrift, vol. 130, no. 34, pp. 1173-1184, 2000.

[61] I. Gerhard, U. Abel, A. Loewe-Mesch, S. Huppmann, and J. J. Kuehn, "Problematik randomisierter studien in der komplementärmedizin dargestellt am beispiel der misteltherapie bei patientinnen mit mammakarzinom," Complementary Medicine Research, vol. 11, no. 3, pp. 150-157, 2004. 
[62] H. J. Hamre, M. Fischer, M. Heger et al., "Anthroposophic vs. conventional therapy of acute respiratory and ear infections," Wiener Klinische Wochenschrift, vol. 117, no. 7-8, pp. 256-268, 2005.

[63] A. Sertkaya, H.-H. Wong, A. Jessup, and T. Beleche, "Key cost drivers of pharmaceutical clinical trials in the United States," Clinical Trials, vol. 13, no. 2, pp. 117-126, 2016.

[64] O. G. Raz, N. Samuels, S. Shalev, and E. Ben-Arye, "Climbing jacob's ladder: overcoming the threshold of death," Journal of Clinical Oncology, vol. 35, no. 16, pp. 1855-1856, 2017.

[65] M. Carey, S. Lambert, R. Smits, C. Paul, R. Sanson-Fisher, and T. Clinton-McHarg, "The unfulfilled promise: a systematic review of interventions to reduce the unmet supportive care needs of cancer patients," Supportive Care in Cancer, vol. 20, no. 2, pp. 207-219, 2012.

[66] R. Sanson-Fisher, A. Girgis, A. Boyes, B. Bonevski, L. Burton, and P Cook, "The unmet supportive care needs of patients with cancer," Cancer, vol. 88, no. 1, pp. 226-237, 2000.

[67] D. Moher, K. F. Schulz, I. Simera, and D. G. Altman, "Guidance for developers of health research reporting guidelines," PLoS Medicine, vol. 7, no. 2, Article ID e1000217, 2010.

[68] P. L. Williams and C. Webb, "The Delphi technique: a methodological discussion," Journal of Advanced Nursing, vol. 19, no. 1, pp. 180-186, 1994.

[69] H. J. Hamre, C. Becker-Witt, A. Glockmann, R. Ziegler, S. N. Willich, and H. Kiene, "Anthroposophic therapies in chronic disease: the anthroposophic medicine outcome study (AMOS)," European Journal of Medical Research, vol. 9, no. 7, pp. 351-360, 2004.

[70] H. J. Hamre, H. Kiene, R. Ziegler et al., "Overview of the publications from the anthroposophic medicine outcomes study (AMOS): a whole system evaluation study," Global Advances in Health and Medicine, vol. 3, no. 1, pp. 54-70, 2014.

[71] H. J. Hamre, V. N. Pham, C. Kern et al., "A 4-year nonrandomized comparative phase-IV study of early rheumatoid arthritis: integrative anthroposophic medicine for patients with preference against DMARDs versus conventional therapy including DMARDs for patients without preference," Patient Preference and Adherence, vol. 2018, no. 12, pp. 375-397, 2018.

[72] C. Paterson, "Measuring outcomes in primary care: a patient generated measure, MYMOP, compared with the SF-36 health survey," BMJ, vol. 312, no. 7037, pp. 1016-1020, 1996.

[73] P. Heusser, S. B. Braun, M. Bertschy et al., "Palliative inpatient cancer treatment in an anthroposophic hospital: II. Quality of life during and after stationary treatment, and subjective treatment benefits," Complementary Medicine Research, vol. 13, no. 3, pp. 156-166, 2006.

[74] D. Schwartz and J. Lellouch, "Explanatory and pragmatic attitudes in therapeutical trials," Journal of Chronic Diseases, vol. 20 , no. 8, pp. 637-648, 1967.

[75] H. J. Hamre, A. Glockmann, G. S. Kienle, and H. Kiene, "Combined bias suppression in single-arm therapy studies," Journal of Evaluation in Clinical Practice, vol. 14, no. 5, pp. 923-929, 2008.

[76] H. J. Hamre, A. Glockmann, W. Tröger, G. S. Kienle, and H. Kiene, "Assessing the order of magnitude of outcomes in single-arm cohorts through systematic comparison with corresponding cohorts: an example from the AMOS study," BMC Medical Research Methodology, vol. 8, no. 1, p. 11, 2008.

[77] A. Fretheim, F. Zhang, D. Ross-Degnan et al., "A reanalysis of cluster randomized trials showed interrupted time-series studies were valuable in health system evaluation," Journal of Clinical Epidemiology, vol. 68, no. 3, pp. 324-333, 2015.

[78] P. C. Rockers, J.-A. Røttingen, I. Shemilt, P. Tugwell, and T. Bärnighausen, "Inclusion of quasi-experimental studies in systematic reviews of health systems research," Health Policy, vol. 119, no. 4, pp. 511-521, 2015.

[79] F. Schad, J. Axtner, A. Happe et al., "Network oncology (NO) - a clinical cancer register for health services research and the evaluation of integrative therapeutic interventions in anthroposophic medicine," Research in Complementary Medicine, vol. 20, no. 5, pp. 353-360, 2013.

[80] W. Tröger, D. Galun, M. Reif, A. Schumann, N. Stanković, and M. Milićević, "Viscum album [L.] extract therapy in patients with locally advanced or metastatic pancreatic cancer: a randomised clinical trial on overall survival," European Journal of Cancer, vol. 49, no. 18, pp. 3788-3797, 2013.

[81] W. Tröger, D. Galun, M. Reif, A. Schumann, N. Stanković, and M. Milićević, "Quality of life of patients with advanced pancreatic cancer during treatment with mistletoe: a randomized controlled trial," Deutsches Aerzteblatt Online, vol. 111, pp. 493-502, 2014.

[82] A. Hoffmann, S. D. Klein, C. Gründemann, M. GarciaKäufer, U. Wolf, and R. Huber, "Efficacy of a nasal spray from Citrus limonand Cydonia oblonga for the treatment of hay fever symptoms-a randomized, placebo controlled cross-over study," Phytotherapy Research, vol. 30, no. 9, pp. 1481-1486, 2016.

[83] H.-R. Metelmann, J. M. Brandner, H. Schumann et al., "Accelerated reepithelialization by triterpenes: proof of concept in the healing of surgical skin lesions," Skin Pharmacology and Physiology, vol. 28, no. 1, pp. 1-11, 2015.

[84] H. J. Hamre, C. M. Witt, A. Glockmann, R. Ziegler, S. N. Willich, and H. Kiene, "Eurythmy therapy in chronic disease: a four-year prospective cohort study," BMC Public Health, vol. 7, no. 1, p. 61, 2007.

[85] T. Von Schoen-Angerer, E. Helmschmidt, R. Madeleyn et al., "A general pediatrics and integrative medicine approach to pervasive refusal syndrome: a case report," The Permanente Journal, vol. 20, pp. 112-115, 2016.

[86] T. R. Frieden, "Evidence for health decision making-sbeyond randomized, controlled trials," New England Journal of Medicine, vol. 377, no. 5, pp. 465-475, 2017.

[87] J. Woodcock and L. M. LaVange, "Master protocols to study multiple therapies, multiple diseases, or both," New England Journal of Medicine, vol. 377, no. 1, pp. 62-70, 2017.

[88] E. Topol, The Creative Destruction of Medicine: How the Digital Recolution Will Create Better Health, Basic Book, New York, NY, USA, 2012.

[89] M. L. Steele, J. Axtner, A. Happe, M. Kroz, H. Matthes, and F. Schad, "Adverse drug reactions and expected effects to therapy with subcutaneous mistletoe extracts (Viscum album L.) in cancer patients," Evidence-Based Complementary and Alternative Medicine, vol. 2014, Article ID 724258, 11 pages, 2014.

[90] U. Weissenstein, M. Kunz, K. Urech, U. Regueiro, and S. Baumgartner, "Interaction of a standardized mistletoe (Viscum album) preparation with antitumor effects of Trastuzumab in vitro," BMC Complementary and Alternative Medicine, vol. 16, no. 1, p. 271, 2016.

[91] A. Thronicke, M. L. Steele, C. Grah, B. Matthes, and F. Schad, "Clinical safety of combined therapy of immune checkpoint inhibitors and Viscum album L. therapy in patients with 
advanced or metastatic cancer," BMC Complementary and Alternative Medicine, vol. 17, p. 534, 2017.

[92] F. Schad, J. Axtner, M. Kröz, H. Matthes, and M. L. Steele, "Safety of combined treatment with monoclonal antibodies and Viscum album L preparations," Integrative Cancer Therapies, vol. 17, no. 1, pp. 41-51, 2018.

[93] I. Shalom-Sharabi, O. Lavie, N. Samuels, L. Keinan-Boker, E. Lev, and E. Ben-Arye, "Can complementary medicine increase adherence to chemotherapy dosing protocol? A controlled study in an integrative oncology setting," Journal of Cancer Research and Clinical Oncology, vol. 143, no. 12, pp. 2535-2543, 2017.

[94] E. T. van der Werf, L. J. Duncan, P. V. Flotow, and E. W. Baars, "Do NHS GP surgeries employing GPs additionally trained in integrative or complementary medicine have lower antibiotic prescribing rates? Retrospective crosssectional analysis of national primary care prescribing data in England in 2016," BMJ Open, vol. 8, no. 3, Article ID e020488, 2018.

[95] H. J. Hamre, A. Glockmann, R. Schwarz et al., "Antibiotic use in children with acute respiratory or ear infections: prospective observational comparison of anthroposophic and conventional treatment under routine primary care conditions," Evidence-Based Complementary and Alternative Medicine, vol. 2014, Article ID 243801, 17 pages, 2014.

[96] H. J. Hamre, C. M. Witt, A. Glockmann et al., "Health costs in patients treated for depression, in patients with depressive symptoms treated for another chronic disorder, and in nondepressed patients: a two-year prospective cohort study in anthroposophic outpatient settings," The European Journal of Health Economics, vol. 11, no. 1, pp. 77-94, 2009.

[97] H. J. Hamre, C. M. Witt, A. Glockmann, R. Ziegler, S. N. Willich, and H. Kiene, "Health costs in anthroposophic therapy users: a two-year prospective cohort study," BMC Health Services Research, vol. 6, no. 1, p. 65, 2006.

[98] P. Kooreman and E. W. Baars, "Patients whose GP knows complementary medicine tend to have lower costs and live longer," The European Journal of Health Economics, vol. 13, no. 6, pp. 769-776, 2012.

[99] S. Petrou and A. Gray, "Economic evaluation using decision analytical modelling: design, conduct, analysis, and reporting," BMJ, vol. 342, no. 111, p. d1766, 2011.

[100] M. Franklin, S. Davis, M. Horspool, W. S. Kua, and S. Julious, "Economic evaluations alongside efficient study designs using large observational datasets: the PLEASANT trial case study," Pharmacoeconomics, vol. 35, no. 5, pp. 561-573, 2017.

[101] S. Petrou and A. Gray, "Economic evaluation alongside randomised controlled trials: design, conduct, analysis, and reporting," BMJ, vol. 342, no. 072, p. d1548, 2011.

[102] D. Husereau, M. Drummond, S. Petrou et al., "Consolidated health economic evaluation reporting standards (CHEERS) statement," Value in Health, vol. 16, no. 2, pp. e1-e5, 2013.

[103] M. C. Weinstein, B. O'Brien, J. Hornberger et al., "Principles of good practice for decision analytic modeling in healthcare evaluation: report of the ISPOR task force on good research practices-modeling studies," Value in Health, vol. 6, no. 1, pp. 9-17, 2003.

[104] G. S. Kienle, H. Kiene, and H. U. Albonico, "[Anthroposophic medicine: health technology assessment reportshort version]," Research in Complementary Medicine, vol. 13, no. S2, pp. 7-18, 2006.

[105] J. J. Gagnier, G. Kienle, D. G. Altman et al., "The CARE guidelines: consensus-based clinical case report guideline development," Journal of Clinical Epidemiology, vol. 67, no. 1, pp. 46-51, 2014

[106] D. S. Riley, M. S. Barber, G. S. Kienle et al., "CARE guidelines for case reports: explanation and elaboration document," Journal of Clinical Epidemiology, vol. 89, pp. 218-235, 2017.

[107] H. Kiene, H. J. Hamre, and G. S. Kienle, "In support of clinical case reports: a system of causality assessment," Global Advances in Health and Medicine, vol. 2, no. 2, pp. 64-75, 2013.

[108] H. Kiene, Komplementäre Methodenlehre der Klinischen Forschung. Cognition-Based Medicine, Springer-Verlag, Berlin, Germany, 2001.

[109] J. K. Aronson and M. Hauben, "Anecdotes that provide definitive evidence," BMJ, vol. 333, no. 7581, pp. 1267-1269, 2006.

[110] G. S. Kienle and H. Kiene, "Clinical judgement and the medical profession," Journal of Evaluation in Clinical Practice, vol. 17, no. 4, pp. 621-627, 2011.

[111] M. Koithan, I. R. Bell, K. Niemeyer, and D. Pincus, "A complex systems science perspective for whole systems of complementary and alternative medicine research," Research in Complementary Medicine, vol. 19, no. S1, pp. 7-14, 2012.

[112] A. Howerter, T. Hollenstein, H. Boon, K. Niemeyer, and D. Brule, "State-space grid analysis: applications for clinical whole systems complementary and alternative medicine research," Research in Complementary Medicine, vol. 19, no. S1, pp. 30-35, 2012.

[113] C. Steinborn, O. Potterat, U. Meyer et al., "In vitro antiinflammatory effects of equisetum arvense are not solely mediated by silica," Planta Medica, vol. 84, no. 8, pp. 519526, 2018 .

[114] N. Beztsinna, M. B. C. de Matos, J. Walther et al., "Quantitative analysis of receptor-mediated uptake and pro-apoptotic activity of mistletoe lectin-1 by high content imaging," Scientific Reports, vol. 8, no. 1, p. 2768, 2018.

[115] A. Büssing, P. F. Matthiessen, and T. Ostermann, "Engagement of patients in religious and spiritual practices: confirmatory results with the SpREUK-P 1.1 questionnaire as a tool of quality of life research," Health Qual Life Outcomes, vol. 3, no. 1, p. 35, 2005.

[116] M. Kröz, R. Zerm, M. Reif et al., "Validation of the German version of the cancer fatigue scale (CFS-D)," European Journal of Cancer Care, vol. 17, pp. 33-41, 2008.

[117] P. Heusser, Anthroposophy and Science: An Introduction, Peter Lang GmbH, Frankfurt am Main, Germany, 2016.

[118] B. Rosslenbroich, "Outline of a concept for organismic systems biology," Seminars in Cancer Biology, vol. 21, no. 3, pp. 156-164, 2011.

[119] B. Rosslenbroich, "Properties of life: toward a coherent understanding of the organism," Acta Biotheoretica, vol. 64, no. 3, pp. 277-307, 2016.

[120] B. Franzel, M. Schwiegershausen, P. Heusser, and B. Berger, "Individualised medicine from the perspectives of patients using complementary therapies: a meta-ethnography approach," BMC Complementary and Alternative Medicine, vol. 13, p. 124, 2013.

[121] E. W. Baars, E. B. Koster, and J. Verhoef, "The contribution of anthroposophic medicine to self-management: an exploration of concepts, evidence, and patient perspectives," Complementary Medicine Research, vol. 24, no. 4, pp. 225231, 2017.

[122] A. Büssing, A. Janko, K. Baumann, N. C. Hvidt, and A. Kopf, "Spiritual needs among patients with chronic pain diseases and cancer living in a secular society," Pain Medicine, vol. 14, no. 9, pp. 1362-1373, 2013. 
[123] E. B. Koster, E. W. Baars, and D. M. J. Delnoij, "Patientcentered outcomes on quality of life and anthroposophic healthcare: a qualitative triangulation study," Quality of Life Research, vol. 25, no. 9, pp. 2257-2267, 2016.

[124] B. Berger, D. Sethe, D. Hilgard, D. Martin, and P. Heusser, "Design of a self-management program for children aged 6-12 Years with type 1 diabetes mellitus at the community hospital Herdecke, Germany," Complementary Medicine Research, vol. 24, no. 4, pp. 255-263, 2017.

[125] B. Berger, C. Schwarz, and P. Heusser, "Watchful waiting or induction of labour-a matter of informed choice: identification, analysis and critical appraisal of decision aids and patient information regarding care options for women with uncomplicated singleton late and post term pregnancies: a review," BMC Complementary and Alternative Medicine, vol. 15, no. 1, p. 143, 2015.

[126] C. Scheffer, D. Tauschel, M. Neumann, G. Lutz, M. ValkDraad, and F. Edelhauser, "Active student participation may enhance patient centeredness: patients' assessments of the clinical education ward for integrative medicine," EvidenceBased Complementary and Alternative Medicine, vol. 2013, Article ID 743832, 8 pages, 2013.

[127] C. Scheffer, M. P. Valk-Draad, D. Tauschel et al., "Students with an autonomous role in hospital care-patients perceptions," Medical Teacher, vol. 40, no. 9, pp. 944-952, 2018.

[128] P. Heusser, S. Eberhard, B. Berger, J. Weinzirl, and P. Orlow, "The subjectively perceived quality of postgraduate medical training in integrative medicine within the public healthcare systems of Germany and Switzerland: the example of anthroposophic hospitals," BMC Complementary and Alternative Medicine, vol. 14, p. 191, 2014.

[129] J. Brockhaus, F. Edelhäuser, D. Tauschel, M. Thye, and C. Scheffer, "“Idealism became viable, something I can put into practice": the meaning of an integrated curriculum for anthroposophic medicine for its graduates," The Journal of Alternative and Complementary Medicine, vol. 20, no. 5, pp. A99-A100, 2014.

[130] E. Ben-Arye, Y. Keshet, M. Livas, and T. Breitkreuz, "Crossing the death threshold: experiencing multi-disciplinary end-of-life integrative oncology training," Supportive Care in Cancer, vol. 26, no. 7, pp. 2251-2257, 2018.

[131] A. Büssing, Z. Falkenberg, C. Schoppe, D. R. Recchia, and D. Poier, "Work stress associated cool down reactions among nurses and hospital physicians and their relation to burnout symptoms," BMC Health Services Research, vol. 17, no. 1, p. 551, 2017.

[132] H. Kiene and H. Heimpel, "Ärztliche professionalität und komplementärmedizin: was ist seriöses therapieren?," Dtsch Arztebl, vol. 107, no. 12, 2010.

[133] M. Huber, J. A. Knottnerus, L. Green et al., "How should we define health?," BMJ, vol. 343, no. 262, p. d4163, 2011.

[134] H. F. Fischer, S. Binting, A. Bockelbrink et al., "The effect of attending steiner schools during childhood on health in adulthood: a multicentre cross-sectional study," PLoS One, vol. 8, no. 9, Article ID e73135, 2013.

[135] I. Chalmers, M. B. Bracken, B. Djulbegovic et al., "How to increase value and reduce waste when research priorities are set," The Lancet, vol. 383, no. 9912, pp. 156-165, 2014.

[136] A.-W. Chan, F. Song, A. Vickers et al., "Increasing value and reducing waste: addressing inaccessible research," The Lancet, vol. 383, no. 9913, pp. 257-266, 2014.

[137] J. P. A. Ioannidis, S. Greenland, M. A. Hlatky et al., "Increasing value and reducing waste in research design, conduct, and analysis," The Lancet, vol. 383, no. 9912, pp. 166-175, 2014. 


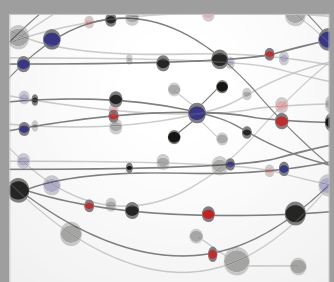

The Scientific World Journal
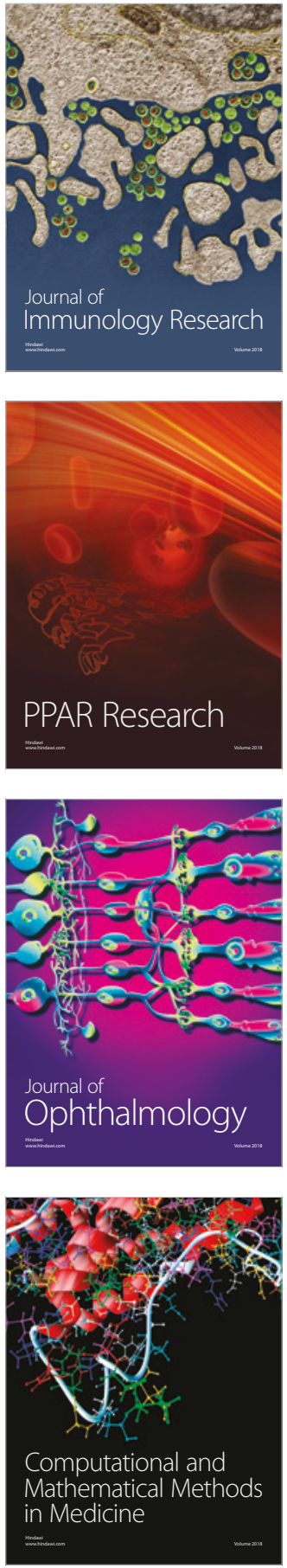

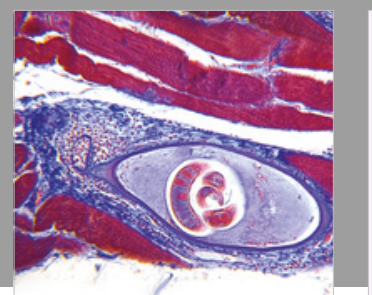

Gastroenterology Research and Practice

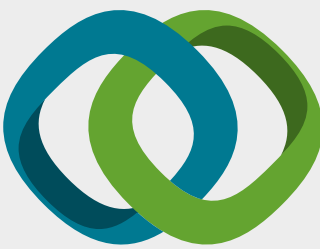

\section{Hindawi}

Submit your manuscripts at

www.hindawi.com
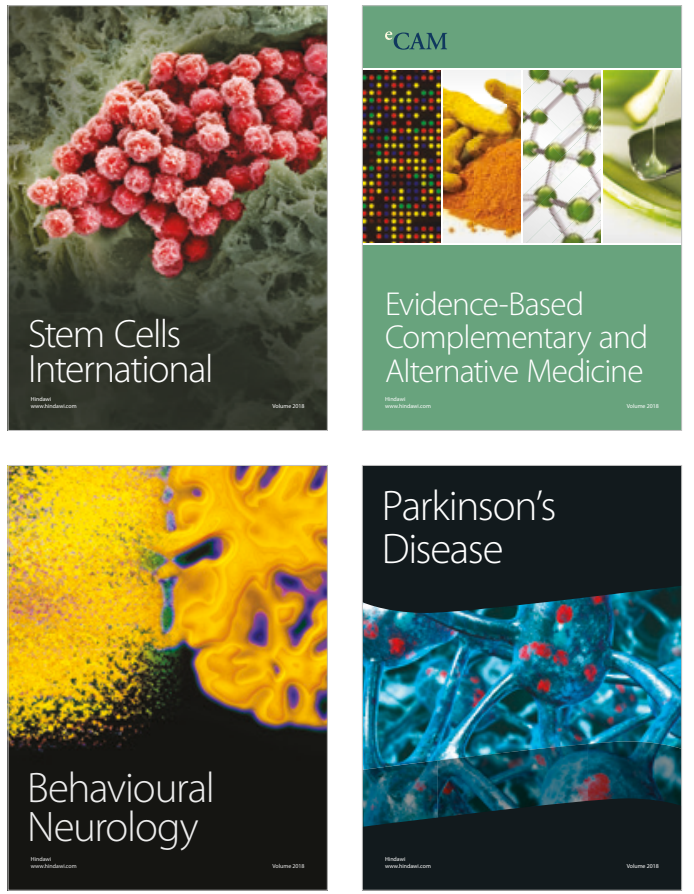

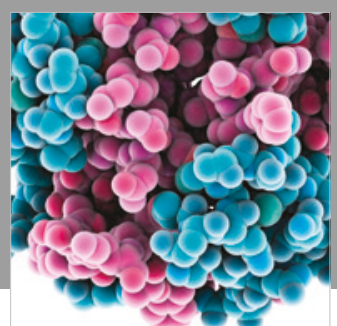

ournal of

Diabetes Research

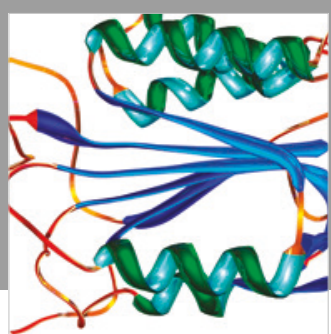

Disease Markers
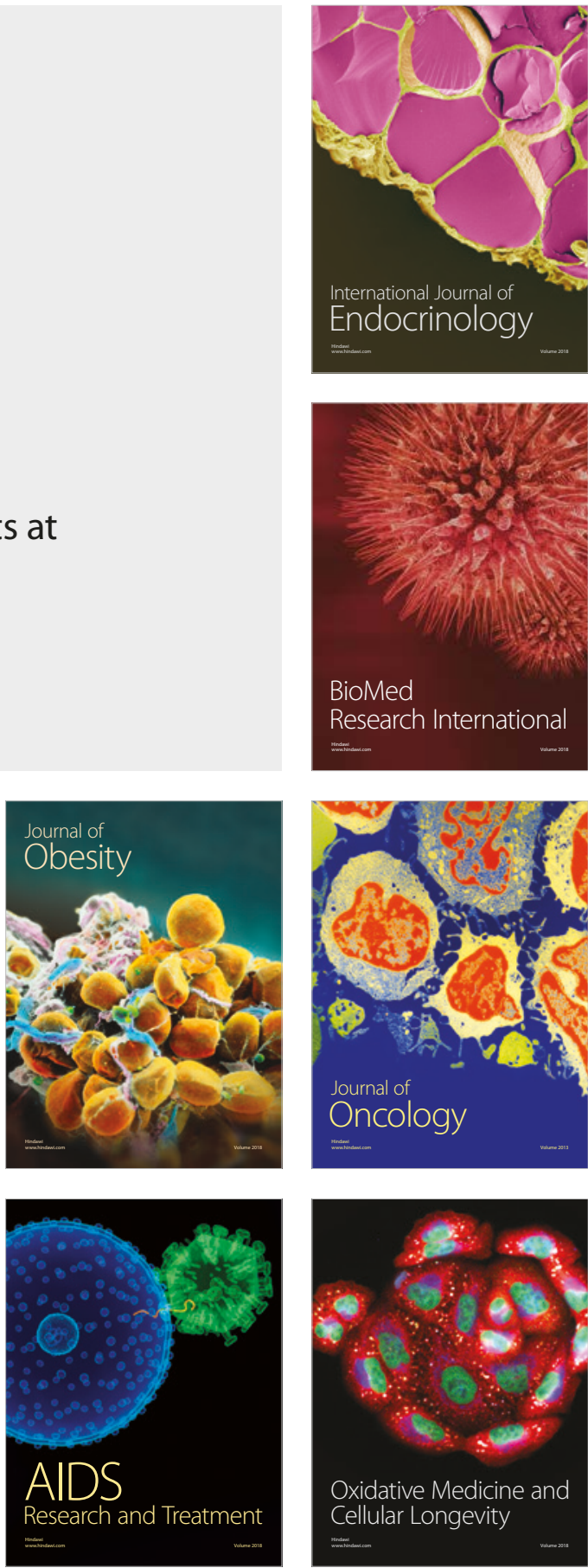